\title{
Low Cost Carrier Competition and Route Entry in an Emerging but Regulated Aviation Market - the Case of China
}

\author{
XIAOWEN FU \\ Institute of Transport and Logistics Studies \\ The University of Sydney \\ E-mail: xiaowen.fu@sydney.edu.au \\ ZHENG LEI* \\ Centre for Aviation Research \\ University of Surrey \\ *Corresponding Author, E-mail: zheng.lei@surrey.ac.uk \\ KUN WANG \\ Sauder School of Business \\ University of British Columbia \\ E-mail: kun.wang@sauder.ubc.ca \\ JIA YAN \\ School of Economics Sciences \\ Washington State University \\ E-mail: jiay@wsu.edu
}

Acknowledgements: We would like to thank helpful comments provided by three anonymous referees, the editor of the special issue, and participants of the 17th ATRS (Air Transport Research Society) conference held in Bergamo, Italy. Financial supports from the University of Sydney Business School (General Research Grant) are gratefully acknowledged. All remaining errors are ours. 


\title{
Low Cost Carrier Competition and Route Entry in an Emerging but Regulated Aviation Market - the Case of China
}

\begin{abstract}
Although China lags behind other liberalized aviation markets in low cost carrier (LCC) development, its largest LCC, Spring Airlines, has achieved rapid growth in traffic volume and revenue, as well as consistent profitability, since its inauguration in 2005. Our empirical study on the Chinese domestic market suggests that Spring adopts a "cream skimming" strategy to enter high-priced routes, allowing the carrier to achieve both a very high load factor and considerable profitability. Spring's capacity and market share on individual routes are constrained to low levels, likely due to government regulation and/or a "puppy dog" strategy adopted by the carrier. As a result, Spring is able to achieve fast growth without triggering price wars. To incumbent full service carriers, high speed rail (HSR) services impose much more significant competitive pressure than low cost carriers. Similar to LCCs in developed markets, Spring prefers to serve markets with high traffic volumes out of its operational base in Shanghai. Overall, Spring's entry decision is not significantly affected by competition, either from full service airlines or HSR services. Our investigation suggests that LCCs have potential to introduce more competition but are yet to be a "game changer" in China. further deregulation of the domestic market is needed.
\end{abstract}

Keyword: Chinese aviation industry, low cost carrier, Spring Airlines 


\section{Introduction}

The Chinese aviation industry has experienced rapid growth during recent decades. The number of air passengers grew at an annualized rate of 14.9\% between 1990 and 2010 (CAAC 2012), and since 2005 China has been the world's second largest aviation market in terms of scheduled capacity. Despite such phenomenal growth, some legacy regulations remain untouched and the aviation market exhibits some distinctive characteristics in terms of network configuration, inter-modal competition, airline cost competitiveness and profitability (Zhang and Chen 2003; Pan et al., 2007; Liu et al., 2009; Lei and O'Connell, 2011; Fu et al., 2012; Lau et al., 2012; Zhang et al., 2013; Wang et al., 2014a, 2014b). Among others, one puzzling feature is the extremely low penetration rate of low cost carriers (LCCs). As of June 2013, there is only one LCC, the Shanghai-based Spring Airlines, serving the domestic market. Although Spring has been consistently profitable since its establishment, it has not brought about the significant fare reduction and traffic volume increase triggered by successful LCCs in deregulated markets. After several years' development, the LCC sector accounts for less than $3 \%$ of the Chinese domestic market, with no new entrant $\mathrm{LCCs}^{1}$. There has not yet been a clear explanation for the under-development of the LCC market in China, despite the success of Spring Airlines.

Both facilitating and impedimentary factors for LCC growth can be found in China. On the positive side, the market for tourists and so-called "visiting friends and relatives" (VFR) travelers has grown rapidly due to strong economic growth and an increasing middle class population in China. ${ }^{2}$ Leisure passengers accounted for about half of the Chinese aviation

\footnotetext{
${ }^{1}$ China West Air, a subsidiary of the Hainan Airline Group based in Chongqing, has announced its intention to transform into a low-cost carrier (CAPA report in July 2013, http://centreforaviation.com/analysis/hnas-chinawest-air-to-become-a-low-cost-carrier--the-catalyst-for-a-lcc-boom-in-china-117061). During our interviews with senior executives of the airline in Sep 2012, we learned that the airline had been profitable, with load factors generally above $90 \%$.

${ }^{2}$ Ernst \& Young (2013) estimated that the middle class population in China was around 150 million, and as many as 500 million Chinese could enter the global middle class over the next decade. McKinsey \& Company (2013) concluded that as of 2012, 71\% of urban households in China could be classified as "mass middle class", "upper middle class" and "affluent". This number could increase to $84 \%$ by 2022.
} 
market in 2010, growing from only 30\% in 1999 (CAMIC 2010). These leisure travelers are likely to be price sensitive, and as such are an ideal market segment for LCCs. Despite fast growth, air travel propensity in China is still low, only 0.24 in 2012 (see Figure 1 (b)). This number is expected to grow substantially in the years to come as the average income level in China continues to increase with the overall economy (See Figure 1(a)). Although few cities have a secondary airport, the total number of commercial airports in China has increased from about 130 to nearly 190 over the past decade, and is expected to reach 230 by 2015 (CAAC $2011)^{3}$. There are an increasing number of small and medium-sized airports which operate under capacity. Many of these airports have been commercialized and/or (partially) privatized, and as such have strong incentives to increase traffic throughput to improve their financial performance. The progressive liberalization in international markets ${ }^{4}$ has allowed carriers like Spring to enter into some overseas markets. The ticket distribution market is becoming competitive. According to CNNIC (2014), 12.1\% of the internet-users in China booked air tickets online in 2013, and a total of 181 million Chinese used online portals to book air tickets, train tickets, hotels and travel packages. Online travel portals such as C-trip and eLong are getting more market shares, which should reduce the market power of the incumbent full service carriers (FSCs). In addition, price regulation has been effectively abandoned since 2002 (Zhang and Round, 2008, 2011). These changes should facilitate the entry of LCCs into the Chinese aviation market and improve their competitiveness.

$<$ Figure 1 here >

\footnotetext{
${ }^{3}$ Currently, only Shanghai is served by two airports. The cities of Beijing and Chengdu are building their second airports. In China's “12th Five-Year Plan for China Civil Aviation Development”, CAAC (2011) decided that priority would be given to capacity expansions at hub airports and building new feeder airports.

${ }^{4} \mathrm{Li}$ et al. (2010) noted that instead of approving substantial regulatory changes all at once, some regulators adopted a progressive liberalization strategy by removing various restrictions gradually, or progressively increasing the upper limits on number of destinations and number of airlines into the markets. It appears that China has largely followed such a strategy. For example, China revised its Bilateral Service Agreement (BSA) with the US in 1994, 1999, 2004, 2007 respectively without committing any (full) open-skies agreements. For more discussions on the liberalization process of China, please refer to Zhang and Chen (2003), Lei and O’Connell (2011), and Fu et al. (2014).
} 
However, LCCs may face some explicit and implicit impediments in serving the market. The Chinese aviation market is very concentrated, with the top 10 airports accounting for approximately half of the domestic market in terms of scheduled capacity (Fu et al., 2012). Most of these large airports are experiencing capacity shortages, making it difficult for new airlines to get desired slots. In addition, airlines still face some constraints in aircraft purchase and pilot recruitment. Li and Zheng (2008) concluded that $80 \%$ of the costs incurred by Chinese airlines are uncontrollable, because the fuel supply, airport charges and taxes are all regulated. There may be limited room for an airline to reduce its operating costs substantially. Finally, although many Asian LCCs have aggressively expanded into international markets (Homsombat et al., 2011, 2014), China is conservative in aviation liberalization and it has been quite challenging for private airlines to serve international destinations (Fu et al., 2010, Adler et al., 2014). In summary, there are both positive and negative factors influencing LCC development in China, but no study has yet provided a convincing explanation for the paradox of the stagnant LCC development in China despite the sustained profitability of Spring Airlines.

Numerous studies have been carried out on LCCs in developed countries where aviation markets are fully deregulated. The effects that LCCs have on pricing have been well documented. In general, competition from LCCs lowers the FSC prices on a route substantially and stimulates significant traffic volumes on the route and in adjacent markets (Whinston and Collins, 1992; Windle and Dresner, 1995, 1999; Dresner et al., 1996; Richards, 1996; Morrison, 2001; Hofer et al., 2008). Morrison (2001) estimated that Southwest, the largest LCC in North America, saved U.S. air passengers US\$12.9 billion in 1998, equivalent to $20 \%$ of the revenue for the domestic passenger market. Boguslaski et al. (2004) examined Southwest's route entry during 1990-2000 and confirmed that the airline was more likely to enter dense routes and to target low income and leisure passengers. Southwest avoided operating at other FSCs' hub airports and tended to expand its network from airports where it already provided services, with a preference for short- to medium-haul routes. Oliveira (2008) 
investigated the entry pattern of Gol, Brazil's most successful LCC. His study concluded that at an early stage, Gol adopted an entry strategy similar to that of Southwest to enter short haul and dense markets. Over time, however, Gol added more long-haul routes into its network. Fu et al. (2011) estimated an almost ideal demand system (AIDS) for passenger services out of Chicago. Their estimation confirmed that there is significant product differentiation between FSCs and LCCs and that an airline's fares are sensitive to competition from carriers of the same type (i.e. LCC pricing is more sensitive to competition from other LCCs than from FSCs).

If the results obtained from these studies can be directly applied to the Chinese aviation market, one would expect intense price competition between LCCs and FSCs, especially on dense, short-distance routes linking secondary airports. This should lead to a high penetration rate of LCC services in the leisure market. However, as described in Section 2 below, this is not what has been observed in the Chinese aviation market. Such a discrepancy between theoretical prediction and actual market outcome calls for an empirical investigation into LCC development in China. Therefore, this study aims to assess Spring's effects on pricing and to investigate its route entry pattern. The contribution of this study to the literature is two-fold. It complements LCC studies in developed markets and helps us to better understand LCC operation and competition. It also provides much needed insight into the Chinese aviation market and assists policy-makers in creating effective strategies to promote industry growth.

This paper is organized as follows. Section 2 provides a general background of Spring Airlines and relevant policy developments in the Chinese domestic markets. In Section 3, reduced form fare equations are estimated to identify Spring's pricing strategy and competitive effects on incumbent FSCs. Section 4 examines Spring's route entry pattern, and the last section summarizes and concludes this study.

\section{Background of Spring Airlines}

Spring Airlines, founded by Shanghai Spring International Travel Services (Spring Travel) in 2005, was the only LCC in service in China and one of only two private airlines providing 
passenger services as of early 2013. ${ }^{5}$ Spring Airlines claims itself as a low cost carrier and has indeed followed some operational strategies commonly used by LCCs, such as a standardized fleet (i.e. Airbus A320), (advertised) deep discount fares that are substantially lower than those offered by FSCs, simple cabin services, and exclusively relying on an in-house ticketing system. Since its establishment, the airline has consistently achieved strong growth in fleet and traffic volumes. As summarized in Tables 1 and 2, the number of passengers carried by Spring increased more than eight-fold, surpassing 10 million in 2013. The carrier served only 13 routes with four aircraft in 2006. By 2013, 51 domestic routes were served with 39 aircraft. Spring also extended its services to cover many international destinations, operating 13 international routes to Hong Kong, Macau, Taiwan, Japan, Korea and Southeast Asian countries.

$<$ Table $1 \&$ Table 2 here >

Spring has been able to maintain profitable growth since its inauguration in 2005, achieving a net profit of RMB483 million (US\$74.8 million) in 2011, RMB625 million (US\$99 million) in 2012 and RMB732 million (US\$118.1 million) in 2013. This is a remarkable achievement compared to the volatile performance of other state-owned FSCs, which are much larger in size and have received government support and bailouts during hard times. China Eastern Airlines, the second largest carrier in the country, received a government capital injection of RMB10 billion (US\$1.45 billion) in 2009 and another injection of more than RMB3 billion (US\$0.44 billion) in 2012 to reduce its debt. In 2012, the other two largest airlines, China Southern and Air China, received capital injections of RMB2 billion (US\$0.29 billion) and RMB1 billion (US\$0.15 billion), respectively. Without such government support, private airlines in China face many challenges and few have performed as well as Spring. Okay Airways, China's first private airline established in 2004, originally planned to follow an LCC

\footnotetext{
${ }^{5}$ Since late 2013, CAAC has approved the establishment of several new airlines, including one private LCC by the Junyao Group. In 2014, China Eastern Airlines also announced its plan to convert its subsidiary, the China United Airlines, into an LCC.
} 
model but soon abandoned this plan. Its management blamed the failure on the high proportion of uncontrollable cost and tight regulations by the Civil Aviation Administration of China (CAAC), the regulator in China. The airline experienced both financial challenges and management chaos in 2008, when its passenger services were temporarily suspended. Another private airline, EastStar, went bankrupt and was taken over by Air China after two years' unsuccessful operation. Figure 2 summarizes the traffic volumes measured by revenue passenger kilometers (RPK) for the private airlines that have been established since 2004 . Spring clearly outperformed the rest. Despite Spring's rapid growth and strong brand recognition, its market share in the domestic market is quite low, less than $3 \%$ as of 2012. Excluding a few small airport pairs served by Spring only, the carrier's average market share on a route is only $20 \%$, giving the airline barely any market power.

$<$ Figure 2 here>

For an LCC model to be successful, a carrier has to maintain a substantial cost leadership against FSCs, because FSCs offer better services. However, Chinese airlines face great challenges in reducing costs. Fuel supply in the country is effectively monopolized by a stateowned company, China Aviation Fuel. Airport landing charges are regulated by CAAC and there is usually limited choice of ground-handling service provider, even at large airports. Aircraft purchase has to be approved by CAAC, to ensure high industry utilization rates, which also makes it difficult for airlines to negotiate significant discounts by placing large orders. Li and Zheng (2008) concluded that $80 \%$ of the cost incurred by Chinese airlines was uncontrollable.

Little was known about Spring's cost competitiveness until the airline released an IPO prospect document in 2014. Table 3 compares the unit operating costs of Spring to the "Big Three" airlines. Overall, Spring achieved unit operating costs 30-40\% lower than major FSCs. This remarkable leadership was achieved through several means: the airline used a fleet consisting of only A320 airplanes, which have an average age of 3.6 years and dense seat 
configurations. ${ }^{6}$ The aircraft utilization rate is more than 11 hours per day, which is about 2 hours above the industry average. In addition, Spring's parent company, Spring Travel, is one of the largest travel agencies in the domestic market. As of late 2012, Spring Travel had 60 wholly-owned subsidiaries, managing a total of 4,000 travel agencies. This extensive network has given Spring an edge in ticket distribution. Spring is also the only carrier in China relying on an in-house ticketing system, independent of the GDS owned by TravelSky. TravelSky's reservation system monopolies the rest of the Chinese market for domestic travel. The inhouse system reduces Spring's distribution costs: the average cost of selling and marketing was $0.009 \mathrm{RMB} / \mathrm{ASK}$ (available seat kilometers) in 2013, substantially lower than the costs of other FSCs (Table 3). Spring's affiliation with its parent travel company also contributes to its ultra-high load factor, which averaged around 95\% during 2005- 2013. ${ }^{7}$

$<$ Table 3 here $>$

Spring's success can also be partially attributed to the location of its operational base in Shanghai, the largest economic center in China. According to China Statistical Yearbook 2013, the city has the highest personal disposable income (RMB40,188 per person vs. national average of RMB24,565 in 2012) and expenditure on transportation (RMB3,221 per person vs. national average of RMB 1,628 in 2012) in China, both of which have been increasing fast thanks to strong economic growth in the region. The income elasticity of leisure air travel is about two (Graham, 2000; Njegovan, 2006). Shanghai thus provides LCCs with a large and fast-growing market, which is important because private airlines in China have somewhat restricted access to capital in the early years of their operation. In comparison, other private airlines formed between 2004 and 2006 were based in Central and Western China, where per capita income is much lower. Spring claims that most of its customers are high-income professionals, including white collar employees (52\%), senior management (14\%), civil

\footnotetext{
${ }^{6}$ For an overview on the effects of fleet standardization on airline productivity, please refer to Zou et al. (2015).

7 Bookings related to group travel contributed less than $20 \%$ of the total sales (number quoted by Spring's executives during an interview in 2012). This implies that the airline's ultra-high load factor is not entirely derived from packaged travel products sold by its parent company.
} 
servants (9\%) and private business owners (8\%). These customers are usually highly educated, making it easier for Spring to introduce e-marketing and self-services (Spring Airlines, 2012).

Regulation in the domestic market, which might have prevented Spring from entering some profitable routes in large scale, could have also helped the carrier by restricting other airlines' entry into Shanghai. Fu et al. (2014) noted that in the Chinese domestic markets, route entry and airport slot allocations are monitored and/or regulated depending on whether hub airports are involved. The details of the regulations have evolved over the years. Before 2010, approvals for route entry were required for most large airports in provincial capital cities and metropolitan areas. Under the current rules, only entries involving the four airports in Beijing, Shanghai, and Guangzhou (i.e. Beijing Capital Airport, Shanghai Hongqiao Airport, Shanghai Pudong Airport, and Guangzhou Baiyun Airport) need to be approved. However, airlines that use these four airports as hubs/operational bases do not need to seek approval for flights from them to other destinations. Therefore, there is no need for Spring to seek approval for flight between Shanghai and Xi'an, but the carrier needs to seek approval for entering the route of or increasing frequency between Beijing and Shanghai. Airport slot allocation process is also ad hoc, although some guidelines have been given to slot allocation committees, which comprises representatives from the regional bureau, regional air traffic control, airlines, and the airport. Fu et al. (2014) concluded that the regulations on both route entry and airport slot allocation in China are more restrictive than those adopted in mature markets such as Europe and North America. Chinese airlines often need to secure approval for both route entry and airport slots when they enter into or add frequencies on routes linking to hubs in metropolitan areas.

In summary, there are both facilitators and impediments to LCC development in China, yet no study has examined these factors systematically. Therefore, a better understanding of the operation and competition strategy of Spring Airlines, the only successful LCC in China to date, would offer valuable insights into Spring Airlines, as well as into the Chinese aviation market in general. Such knowledge would facilitate the entry of other LCCs to the market and 
help policy makers to identify key factors which impede the Chinese aviation industry. In this study, this objective is achieved by empirically studying the pricing effects of Spring and analyzing the airline's route entry pattern.

\section{Spring Airlines' Pricing Effects on FSCs}

Many studies have examined the effects of LCCs on airline pricing. Windle and Dersner (1995), Morrison and Winston (1995) and Morrison (2001) estimated reduced form fare equations and concluded that the presence of Southwest significantly reduced average prices on the routes. Another group of studies simultaneously estimated a fare equation and a demand function to identify parameters related to both passenger demand and supply (e.g. Richard, 1996, Dresner et al., 1996, Windle and Dresner, 1999). The actual traffic volumes of each airline are unavailable in our study. As a result, only one reduced form fare equation can be estimated using exogenous variables related to route and airport characteristics. In addition, the fares of FSCs can be estimated using GDS reservation data, but price data for Spring are not available because the carrier uses its own reservation system. Therefore, we choose to examine the effects of Spring's presence on the fares of competing FSCs on the same route. We use an econometric model similar to that of Morrison and Winston (1995). The reduced form model is specified as in equation (1).

(1) $\ln$ Yield $_{j, t}=\alpha_{0}+\alpha_{1} \ln$ Dist $_{j}+\alpha_{2} \ln H H I_{j, t}+\alpha_{3} \ln$ AirShare $_{j, t}+\alpha_{4} \ln$ AirportVol $_{j, t}+$

$$
\begin{aligned}
& \alpha_{5} \text { Tour }_{j}+\alpha_{5} \text { HSR }_{j, t}+\alpha_{6} \text { Spring }_{j, t}+\sum_{r=1} \theta_{r} \text { FSC }_{r j t}+ \\
& \sum_{r=1} \gamma_{r} \text { Quarter }_{r j t}+\sum_{r=1} \mu_{r} \text { Year }_{r j t}+\tau_{j}+\varepsilon_{j, t},
\end{aligned}
$$

where

Yield $_{j, t}$ : an FSC's average yield on route $j$ in time $t$;

Dist $_{j}$ : flying distance for route $j$;

$H H I_{j, t}$ : Herfindahl Hirschman Index for route $j$ in time $t$, computed based on airlines' scheduled seats on the route;

AirShare $_{j, t}$ : product of an FSC's market shares (scheduled seats) in origin and destination (OD) airports of route $j$ in time $t$;

AirportVol $_{j, t}$ : product of OD airports' total traffic volumes (scheduled seats) for route $j$ in time $t$ 
Tour $_{j}$ : dummy variable equal to 1 if at least one airport on route $j$ is a tourist destination. In our sample, tourist destinations include the following airports: Kunming, Guilin, Lijiang, Xi'an, Lhasa, Haikou, Sanya and Hailar; ${ }^{8}$

$H S R_{j, t}$ : dummy variable equal to 1 if direct high-speed rail (HSR) service is available on route $j$ in time $t$; Two alternative specifications are tested. Variable HSR_1 considers rail service with a maximum speed above $200 \mathrm{~km} / \mathrm{hr}$; HSR_2 only considers rail service with a maximum speed above $300 \mathrm{~km} / \mathrm{hr}$.

Spring $_{j t}$ : dummy variable for Spring airlines' presence on route $j$ in time $t$;

$F S C_{r j t}$ : FSC dummies reflecting a major FSC's presence on route $j$ in time $t$;

Quarter $_{r j t}$ : quarterly dummies;

Year $_{r j t}$ : yearly dummies;

$\tau_{j}$ : route unobservable and time-invariant factor;

$\varepsilon_{j, t}:$ white noise.

This reduced form fare equation is estimated with the dependent variable being the yield of the four largest Chinese FSCs respectively. These four airlines, namely state-owned Air China, China Eastern and China Southern (the "Big Three"), and the fourth largest carrier Hainan airlines, dominate the Chinese domestic market. Their pricing behavior should play important roles in setting the competition scenarios on a route and thus serve as good proxies for market fare levels. To control for possible airline-specific effects, the average yield of all four FSCs on a route is also tested as the dependent variable.

The explanatory variable of interest is the dummy variable $S_{p r i n g}{ }_{j, t}$, which is set to 1 if Spring operates on this route. Flying distance Dist $_{j}$ is included because yield usually decreases with stage length in a route. AirportVol ${ }_{j, t}$ controls for endpoint airport sizes on one route. It captures the market potential as geo-economic variables such as population and income level. The $H H I_{j, t}$ index measures market concentration, which serves as a proxy for market competition at route level. It is expected that fares should be higher on more concentrated routes. AirShare $M_{j, t}$ reflects the airline's presence at endpoint airports of a route. Intuitively, when airlines possess larger market shares in origin-destination (OD) airports, they are able to charge higher prices, a benefit similar to the "hub-premium"

\footnotetext{
${ }^{8}$ The Tour dummy is defined for popular tourist destinations in China. A similar definition was used by Zhang and Round (2009). Morrison (2001) defined a "sun belt" dummy for tourist destinations in the US. These specifications could be subjective. Where data are available, objective measures such as tourism industry's share of local GDP may be better indicators.
} 
identified in previous studies (Borenstein, 1989). During the past decade, high-speed rail (HSR) services had experienced tremendous growth. Although Fu et al. (2012) qualitatively discussed possible competition between HSR services and airlines, few studies have empirically investigated such an issue. In our econometric model, an availability dummy is defined for HSR services. Two alternative definitions are considered. The "HSR_1" is defined for rail services with a designed maximum speed above 200km/hr. Variable HSR_2 only considers services with a maximum speed above $300 \mathrm{~km} / \mathrm{hr}$. Lastly, tourist route and time effects are also controlled by dummy variables.

Monthly panel data are compiled, covering a total of 514 city-pair routes in the domestic market (the top 500 routes plus a few smaller routes served by Spring Airlines), with a time span from August 2008 to July 2012. Ticket price data are compiled from PaxIS, a GDS database that records reservation transactions maintained by the IATA. The average price of all fare classes is computed for each airline, apart from Spring Airlines, on a non-directional basis. The OAG database is used for route distance and the number of scheduled seats. An airline is regarded as serving a route when its scheduled capacity exceeds 1,000 seats per month. This definition is used to remove data from occasional charter services or ferry flights. To ensure consistency between the PaxIS and OAG databases, ticket prices in PaxIS are used only if the airline's service on this route is also reported in OAG. Descriptive statistics of our sample data are summarized in Table 4.

$<$ Table 4 here>

The data for all of the months and routes are first pooled and estimated with ordinary least squares (OLS). Surprisingly, the Spring dummy has a positive sign when the dependent variable is the average yield of all FSCs on a route and when the dependent variable is the yield of China Eastern or China Southern. This is because a simple OLS estimation over pooled data does not control for the route unobservable factor $\tau_{j}$. As a result, the Spring dummy captures part of the unobservable route characteristics. The positive sign for the 
Spring dummy indicates that ceteris paribus, routes with Spring service had higher ticket prices than those without. On average, China Eastern's yield on routes with Spring presence was $4 \%$ higher than the routes without, whereas China Southern maintained a $5.5 \%$ higher fare on routes with Spring presence. To identify the true competition effects of Spring on FSCs, the route unobservable factor $\tau_{j}$ has to be controlled. This can be achieved by estimating fixed effect or random effect models. The Hausman Test suggests a fixed effect model as the more appropriate option. The estimation results of OLS and fixed effect models are collated in Table 5.1 and 5.2.

It can be noted that the sign of the Spring dummy becomes negative and is statistically significant. This confirms that competition from Spring did force FSCs to lower their ticket prices. Specifically, the presence of Spring reduced the fare of Air China by 5.1\%, the fare of China Eastern by $3.4 \%$ and the fare of Hainan airlines by $6.2 \%$. Overall, FSCs' fares were reduced by $2.3 \%$ due to competition from Spring. Such a fare reduction is rather small compared to those observed for leading LCCs, such as Southwest in the U.S., and Ryanair in Europe. A paired t-test is conducted to compare the average yields of FSCs before and after Spring's entry. The test confirms that there is a statistically significant decline in FSCs' yields after Spring's entry, although in absolute value the yield only decreased from 8.62 US cents $/ \mathrm{km}$ to 8.01 US cents $/ \mathrm{km}$. The average stage length for routes served by Spring was 1,268 $\mathrm{km}$, thus the fare reduction per route was US\$7.7 (or RMB53) on average. This limited fare reduction may be explained by Spring's low capacity on individual routes. Although the carrier has been expanding its network and fleet, its capacity share on individual routes tends to be low, especially on dense routes dominated by large FSCs. As illustrated in Figure 3, Spring's route capacity share is mostly below $20 \%$ for the dense routes. Therefore, dominant FSCs are not under great pressure to respond with a significant price cut.

Indeed, to incumbent full service carriers HSR services impose much more significant competitive pressure than low cost carriers. According to the estimation results as reported in Table 5.1, on average HSR services (with a maximum speed above $200 \mathrm{kms} / \mathrm{hr}$ ) reduced the 
yield of Air China by $5.1 \%$, the yield of China Eastern by $9.5 \%$, and the yield of China Southern by $11.6 \%$. Overall, FSC airlines' yields were $10.4 \%$ lower due to HSR competition. As reported in Table 5.2, similar estimation results have been obtained when we only consider HSR services with a maximum speed above $300 \mathrm{~km} / \mathrm{hr}$.

<Table 5.1 and 5.2 here>

$<$ Figure 3 here>

Flight frequency may have significant effects over an airline's yield because an increase in flight frequency improves a carrier's service quality through reducing passengers' schedule delay. However, carriers adjust their frequencies frequently in responding to demand shocks. As such, including flight frequencies in reduced-form regressions raises endogeneity concern, as demonstrated in Fu et al. (2011). FSC dummies in Eq (1) represent the carriers' entry decisions, which face significant fixed-costs and cannot therefore be adjusted frequently. Due to the endogeneity issue associated with flight frequencies, we use FSC dummies instead of their flight frequencies in Eq (1) but conduct a robustness check of replacing the FSC dummies with respective FSCs' frequencies. Estimation results of the robustness check, which are reported in the appendix, are similar to our baseline results.

Overall, our estimation results suggest that Spring adopts a "cream-skimming" strategy to selectively enter routes that are high-priced. This may allow Spring to achieve extremely high load factors without offering many deeply discounted tickets. Still, the presence of Spring on a route does impose some competitive pressure on FSCs, leading to moderate fare reductions. This competition pattern is different from those observed in fully deregulated markets, in which LCCs such as Southwest enter routes and provide deep discounts and large capacities or large frequencies (see for example Dresner et al., 1996; Morrison, 2001; Fu et al., 2011).

There is no clear justification for Spring, or any airline, to offer limited capacity on profitable routes. Instead, this is likely due to government regulation. Although route entry restriction 
has been removed for most destinations, there is regulation and effective slot control in major airports, especially those in Beijing, Shanghai and Guangzhou. By establishing its operational base in Shanghai, Spring is well positioned to enter some of the most profitable markets. However, this also implies that the airline will have limited freedom in planning its network expansion and route entries. Another possible explanation is that it may be in Spring's own interests to limit its capacity on individual routes. The airline is a fringe player compared to other dominant FSCs which have large fleets and easy access to capital. Spring will benefit from avoiding price wars and deploying its limited capacity on the most profitable routes. In other words, it may be the airline's choice to adopt a "puppy dog" strategy at the current stage. In the following section, we study Spring's entry decisions.

\section{Route Entry Choice of Spring Airlines}

To identify factors influencing an airline's route entry decisions, a discrete choice model can be estimated based on the observed network pattern of airlines (e.g. Boguslaski et al., 2004; Oliveira, 2008; Homsombat et al., 2014). An airline's decision to serve an airport-pair or not depends on the profit generated from this route market. Although the entry decision of Spring can be identified, the airline's operating profit on each route is unobservable (latent) to researchers. Consider Spring's latent profit $\pi^{*}$ after entering a route to be the following equation (2)

$$
\ln \pi^{*}=\ln x^{\prime} \varphi+\mu
$$

which is a function of a vector of control variables $\boldsymbol{x}^{\prime}$ and a stochastic error term $\mu$. More specifically, the profit function (2) can be specified as the following expression

$$
\begin{aligned}
& \ln \pi_{i}^{*}=\varphi_{0}+\varphi_{1} \ln \text { Dist }_{i}+\varphi_{2} \ln \text { AirportVol }_{i}+\varphi_{3} \ln H H I_{i}+\sum_{r=4} \varphi_{r} \text { Density }_{(r-3) i} \\
& +\varphi_{7} \text { OwnHub }_{i}+\varphi_{8} \text { OtherHub }_{i}+\varphi_{9} \text { HSR }_{j, t}+\mu_{i}
\end{aligned}
$$

where

$\pi_{i}^{*}$ : the latent profit of Spring for serving route $i$ 
Dist $_{i}$ : the flying distance of route $i$;

AirportVol $l_{i}$ : the product of OD airports' scheduled seats for route $i$;

$H H I_{i}:$ HHI index for route $i$;

Density $_{1 i}$ : dummy variable equals to 1 for the top 20 routes in terms of traffic density;

Density $_{2 i}$ : equals 1 for the top $21^{\text {st }}$ to $50^{\text {th }}$ routes in terms of traffic density;

Density $_{3 i}$ : equals 1 for the $51^{\text {st }}$ to $150^{\text {th }}$ routes in terms of traffic density;

$O w n H u b_{i}$ : a dummy variable equals to 1 if one of the OD city for route $i$ is Shanghai.

Shanghai has been the headquarters and operational base for Spring Airlines;

Other $H u b_{i}$ : a dummy variable equaling to 1 if at least one of the OD airports on route $i$ is Beijing or Guangzhou.

$H S R_{j, t}$ : dummy variable equal to 1 if direct high-speed rail (HSR) service is available on route $j$ in time $t$; Two alternative specifications are tested. Variable HSR_1 considers rail service with a maximum speed above $200 \mathrm{~km} / \mathrm{hr}$; HSR_2 only considers rail service with a maximum speed above $300 \mathrm{~km} / \mathrm{hr}$.

Dist $_{i}$ is commonly included in airline entry studies to control for cost and price factors related to flying distance. AirportVol ${ }_{i}$ is the average airport traffic volume of the end points on a route, a proxy for market potential. That is, a route linking two large airports is likely to have large traffic demand. $H H I_{i}$ is used to measure route concentration and thus market competition. The dummy variables Density $_{(r-3) i}$ examine possible effects of route density on entry decision. Dummy variables are used instead of passenger volumes on these routes, because route licensing for dense routes is controlled by the regulator CAAC, especially for the top twenty routes linking the largest hub airports. Thus these density dummies may capture possible regulation effect, which is likely to be discrete rather than continuous. The dummy variable $O w n H u b_{i}$ is included because Spring may gain some advantage by serving routes out of its base in Shanghai. Finally, the dummy variable OtherHub $b_{i}$ related to airports in Beijing and Guangzhou is used to capture possible competitive advantages possessed by Air China and China Southern, which are based in these two airports, respectively. It may be difficult for Spring to acquire slots or to compete with other airlines' fortress hubs (Borenstein, 1989; Zhang, 1996). The dummy variable $H S R_{j, t}$ is included to control possible effects of HSR competition on Spring's route entry decisions. 
Let Spring's entry decision be $Y$ and $C$ be the fixed cost or a profit threshold for Spring to enter a new route (i.e., the minimum profit required for the airline to enter a route, or the opportunity costs associated with a new market entry). The entry decision can be specified as a function of the latent profit function (3), such that $Y_{i}=1$ if $\pi^{*}-C>0$, and $Y_{i}=0$ if $\pi^{*}-$ $C \leq 0$. Thus the probability of route entry can be expressed as:

$$
\operatorname{Prob}\left(Y_{i}=1 \mid \boldsymbol{x}\right)=\operatorname{Prob}\left(\frac{\pi^{*}}{C}>1 \mid \boldsymbol{x}\right)=\operatorname{Prob}\left(\ln \boldsymbol{x}^{\prime} \boldsymbol{\varphi}-\ln C+\mu>0 \mid \boldsymbol{x}\right) .
$$

With the assumption that $\mu_{i} \sim$ iid $N(0,1)$, this probit model can be estimated with a maximum likelihood estimator. Data are mostly compiled from the OAG database, which contains airline scheduled flight information. To screen out occasional charter services and ferry flights, Spring is defined as serving a route only if its monthly scheduled capacity exceeds 1,000 seats for at least three consecutive months. As market equilibrium may be influenced by Spring's presence on a route and adjacent markets, and Spring's entry decision on a route may be dependent on its existing network configuration (i.e. entry decisions in previous years), there are risks of endogeneity if the dependent variable and independent variables are from the same period. Therefore, the values of independent variables (as defined after Eq. 3) are all based on data from 2005, although our study covers Spring's operation during 2005-2012.

Five hundred and fourteen routes are selected, including the top 500 city pairs in the domestic market, based on 2012 scheduled seats, and a few smaller routes served by Spring during the study period. A few observations related to routes not served by any airline before Spring's entry are removed, as the explanatory variables $H H I_{i}$ are in log form and thus are undefined for these observations. Four hundred and ninety-six observations are available for the estimation of the probit model. Descriptive statistics for this sample are reported in Table 6.

<Table 6 here> 
The probit model estimation results are displayed in Table 7, which are based on the specification of HSR1. Using alternative specification of HSR2 yields similar results, which are not reported to save space. The coefficient of flying distance is positive and statistically significant, suggesting that Spring is likely to enter long distance routes. This is different from established LCCs such as Southwest, which prefer short haul routes. In our sample, the average stage length for routes served by Spring is 1,248 kilometers, longer than the sample mean of 1,045 kilometers. Intuitively, this might be due to the competition from HSR services, because HSR services often have a significant advantage over air transport in terms of frequency and cost on medium and short haul routes (Fu et al., 2012, 2014). However, whereas HSR dummy is significant in FSAs' yield estimation, it does not have a significant effect on Spring's route entry decisions. Overall, it seems that Spring's entry decision is not significantly affected by competition, either from full service airlines or HSR services. Spring is likely to enter into many more routes when the domestic market is fully deregulated.

\section{$<$ Table 7 here>}

A reasonably large number of Spring's services are out of secondary cities, such as Lanzhou, Shijiazhuang, Fuzhou and Huaihua, as reflected by the negative coefficient of AirportVol ${ }_{i}$. This entry pattern is in line with LCCs' market positioning for leisure and price-sensitive travelers in secondary cities. In addition, secondary airports are less congested, allowing for quick aircraft turnaround time. It should also be noted that some local governments offer Spring very attractive economic incentives to build up operations. For example, to encourage Spring's operation in local airports, the governments of Hebei, Changde, Huaihua, Mianyang and Jinjiang provide airport charge discounts and cash subsidies to Spring. In 2013 alone, Spring received RMB522 million from various local governments, representing $8 \%$ of its total revenue that year (Spring IPO Prospectus, 2014).

The estimation results also revealed that competition on a route is not an impedimentary factor for Spring, as evidenced by the positive but not significant coefficient of the HHI index. A closer look at the detailed entry pattern reveals that Spring has entered some dense routes in 
the presence of multiple competing airlines. The carrier has also initiated some new routes which had not been served by any airline before. As the pricing study in the previous section suggests, Spring has selectively entered some dense routes which are high-priced. Meanwhile, as the carrier has significantly lower costs than other FSCs, it can serve some very thin routes that are not feasible for high cost FSCs. Although traffic volumes on these routes are limited, Spring may still be able to achieve decent levels of profit with its monopoly status. As a result, Spring has entered routes with both high and low market concentration ratios.

The density dummies Density $_{1 i}$ and Density $_{2 i}$ are significantly positive, indicating that Spring prefers dense routes. However, it is not easy for the carrier to enter the largest routes, such as the top 20 markets. After six-years' preparation and application, Spring finally obtained the approval to serve the Shanghai - Beijing route in 2011, the same year when a high speed rail linking the two cities was put into operation. Table 8 summarizes the distribution of routes with Spring service based on density categories. In 2012, 38\% of Spring's routes ranked within the top 150 markets, at a time when there were 1,393 routes in the domestic market.

$<$ Table 8 here $>$

The positive sign of $O w n H u b_{i}$ suggests that Spring prefers to add routes that operate out of its base at Shanghai. This is intuitive, because adding new services from established bases is cost effective, as it allows a carrier to better use the existing infrastructure. In addition, scheduling more flights at base airports helps Spring to maximize aircraft utilization, because aircraft can be conveniently transferred between routes in case of service disruptions. Spring's daily aircraft utilization is more than 11 hours, which is about $30 \%$ higher than the industry average. Finally, Spring avoids operating in Guangzhou and Beijing, which are the hubs of China Southern and Air China. As competition (measured by HHI index) does not appear to have any effect on Spring's entry decision, this avoidance is probably due to difficulties in obtaining slots and governmental approval in these two airports. 


\section{Conclusion}

Despite the phenomenal growth of the Chinese aviation industry over the past decades, the country's LCC sector is still under-developed. By early 2013, there was only one LCC serving the market, which controlled a negligible share of the domestic market. However, Spring has achieved rapid growth in traffic volume and revenue, as well as consistent profitability, since its inauguration in 2005. There has been no convincing explanation for the success of Spring Airlines despite the under-development of the LCC market. In fact, few empirical investigations have analyzed the LCC sector in China. This study fills this research gap by examining the competition effects brought by Spring to the Chinese domestic market and the carrier's route entry strategy.

Our empirical results suggest that Spring adopts a "cream skimming" strategy to enter highpriced routes, allowing the carrier to achieve both a very high load factor and considerable profitability. Spring's capacity and market shares on individual routes are constrained to low levels, which is likely due to government regulation on route entry and airport slot acquisition, and/or a "puppy dog" strategy adopted by the carrier. As a result, Spring is able to achieve fast growth without triggering price wars with incumbent FSCs. Overall, the carrier has moderately increased competition on the routes, on average reducing the fare of Air China by $5.1 \%$, the fare of China Eastern by $3.4 \%$ and the fare of Hainan Airlines by $6.2 \%$. Similar to LCCs in developed markets, Spring prefers to serve dense markets and routes that operate out of its operational base in Shanghai, Overall, it seems that Spring's entry decision is not significantly affected by competition, either from full service airlines or HSR services. Therefore, Spring's limited services at major airports such as Beijing and Guangzhou are likely due to regulation instead of competition concerns. Spring is likely to enter into many more routes when the domestic market is fully deregulated. 
Despite Spring's strong growth over the years, it is evident that overall LCC development in China still lags far behind that in developed countries, where aviation markets have been fully deregulated. LCCs are yet to be a "game-changer" in China and there are signs that government regulations have inhibited the growth of LCCs. Spring's capacities on profitable routes have been limited and the carrier has not been able to expand its presence at major hub airports and on dense routes. As a result, Spring Airlines has not brought significant changes (e.g., significant price reduction or traffic volume surge) as the major LCCs in North America and Europe. On the other hand, certain regulations may have helped Spring in maintaining high profitability. For example, CAAC temporally froze issuing licenses to new airlines during the period of 2007 to 2013. It is likely that this restriction helped incumbent airlines, including Spring, to block competition from potential entrants, especially private airlines or LCCs that may target the same market segment as Spring. ${ }^{9}$ In addition, as discussed in previous sections, Spring has some unique competitive advantages which cannot be easily replicated by other LCCs (e.g., Spring's parent company is one of the largest travel agents in China, and its operation is based in Shanghai). However, for the development of the aviation industry as a whole, more LCCs need to be formed and further deregulation is needed. This may include the deregulation of aircraft purchase and pilot recruitment, introducing a transparent system of slot allocation at hub airports and allowing LCCs into more international markets.

Although our empirical investigation offers fresh insights into an important market, our study has some limitations. Due to data limitations, we are unable to observe the actual traffic volume of each airline, and thus use scheduled capacities (number of seats) as proxy variables. For the same reason, we cannot estimate a demand function and a fare equation simultaneously, which would have increased estimation efficiency and offered richer information on passenger preferences. In addition, as Spring uses its own reservation system, its fares are not publically available. Although our investigation of competing FSCs' fare changes reveals Spring's

\footnotetext{
${ }^{9}$ We are thankful to two anonymous referees for pointing out the related issues to us.
} 
competitive effects on rival airlines, it does not allow a direct examination of Spring's pricing strategy. It is not clear whether Spring's capacity limitation on most of the routes is intentional (thus the 'puppy-dog strategy') or it is mainly due to regulation (route entry and slot control etc.). Further studies should be carried out when better data are available.

\section{Reference}

Adler N., Fu X., Oum T.H. and Yu C., 2014. Air transport liberalization and airport slot allocation: the case of the Northeast Asian transport market. Transportation Research - Part A, 62, 3-19.

Boguslaski, C., Ito, H., Lee, D., 2004. Entry patterns in the Southwest airlines route system. Review of Industrial Organization 25, 317-350.

Borenstein, S., 1989. Hubs and high fares: dominance and market power in the U.S. airline industry. RAND journal of economics 20, 344-365.

Brander, J., Zhang, A., 1990. Market conduct in the airline industry: an empirical investigation. The RAND Journal of Economics 21, 567-583.

China Internet Network Information Center (CNNIC), 2014. Statistical report of the Internet development status in China, July 2014.

Civil Aviation Administration of China (CAAC), 2011. The 12th five-year plan for China civil aviation development, April 2011.

Civil Aviation Administration of China (CAAC), 2012. Statistical data on civil aviation of China. Various issues, Beijing, 2003-2012.

Civil Aviation Management Institute of China (CAMIC), 2010. An investigation of the market characteristics of civil aviation in 2010. Working paper and industry report (in Chinese).

Dresner, M., Lin, J.-S.C., Windle, R., 1996. The impacts of low-cost carriers on airport and route competition. Journal of Transport Economics and Policy 30, 309-328.

Graham, A., 2000. Demand for leisure air travel and limits to growth. Journal of Air Transport Management 6, 109-118.

Ernst \& Young, 2013. Hitting the sweet spot - the growth of the middle class in emerging markets. Ernst \& Young

Fu X., Oum T.H., Lei Z. and Chen R., 2014, Dominant carrier performance and international liberalization - the case of Northeast Asia. Paper presented at the OECD Special Session of the 2014 ATRS conference, Bordeaux, France.

$\mathrm{Fu}$ X., Oum T.H. and Zhang A., 2010. Air transport liberalization and its impacts on airline competition and air passenger traffic, Transportation Journal, 49(4), 24-41.

Fu, X., Dresner, M., Oum, T.H., 2011. Effects of transport service differentiation in the U.S. domestic airline market. Transportation Research Part E 47(3), 297-305.

Fu, X., Zhang, A., Lei, Z., 2012. Will China's airline industry survive the entry of high-speed rail? Research in Transportation Economics 35, 13-25. 
Fu X., Oum T.H. and Yan J., 2014. An analysis of travel demand in Japan's inter-city market: empirical estimation and policy simulation. Journal of Transport Economics and Policy, 48(1), 97-113.

Hofer C., Windle R., Dresner, M., 2008. Price premiums and low-cost carrier competition. Transportation Research Part E 44 (5), 864-882.

Homsombat W., Lei Z. and Fu, X. 2011. Development status and prospects for aviation hubs - a comparative study of the major airports in South-east Asia. Singapore Economic Review, 56(4), 573-591.

Homsombat W., Lei Z. and Fu X. 2014. Competitive effects of the airlines-within-airlines strategy - pricing and route entry patterns. Transportation Research - Part E, 63, 116.

McKinsey \& Company, 2013. Mapping China's middle class, Insights \& Publications, June 2013.

Lau Y.Y., Lei Z., Fu X., Ng A., 2012. The Implications of the re-establishment of direct links across the Taiwan Strait on the aviation industries in Greater China. Research in Transportation Economics 35, 3-12.

Lei, Z., O'Connell, J. F., 2011. The evolving landscape of Chinese aviation policies and impact of a deregulating environment on Chinese carriers. Journal of Transport Geography, 19, 829-839.

Li Z.C., Lam H.K., Wong S.C. and Fu X., 2010. Optimal route allocation in a liberalizing airline market. Transportation Research - Part B, 44(7), 886-902.

Li, Z., Zheng, Q., 2008. Low cost carrier strategy. Price: Theory \& Practice 8, 66-67.

Liu, W., Luk, K. R., 2009. Reform and opening up: way to the sustainable and harmonious development of air transport in China. Transport Policy 16, 215-223.

Morrison, S.A., Winston, C., 1995. The evolution of the airline industry. The Brookings Institution, Washington, D.C..

Morrison, S.A. ,2001. Actual, adjacent, and potential competition estimating the full effect of Southwest airlines. Journal of Transport Economics and Policy 35, 239-256.

Njegovan, N., 2006. Elasticities of demand for leisure air travel: A system modeling approach. Journal of Air Transport Management 12, 33-39.

Oliveira, A.V.M., 2008. An empirical model of low-cost carrier entry. Transportation Research Part A 42, 673-695.

Pan, K., Cao, Y., Wei, H., Cao, W., 2007. The study on distributing pattern and network structure of air freight airports in China. Economic Geography 27, 653-657.

Richards, K., 1996. The effects of Southwest Airlines on U.S. airline markets. Research in Transportation Economics 4, 33-47.

Spring Airlines, 2012. Creating greater China's top LCC brand. Presentation at the CAPA LCCs and New Age Airlines Conference, Macau, Sep 2012.

Spring Airlines, 2014. Spring Airlines IPO prospectus. Submitted to China Securities Regulatory Commission.

US DOT, 1993. The airline deregulation evolution continues: The Southwest effect. Office of Aviation Analysis, US Department of Transportation. 
Wang K., Fan X., Fu X., Zhou Y., 2014. Benchmarking the performance of Chinese airlines: an investigation of productivity, yield, and cost competitiveness. Journal of Air Transport Management 38, 3-14.

Wang, K., Gong, Q., Fu, X., Fan, X., 2014. Frequency and aircraft size dynamics in a concentrated growth market: The case of the Chinese domestic market. Journal of Air Transport Management 36, 50-58.

Whinston, M.D., Collins, S.C., 1992. Entry and competitive structure in deregulated airline markets: an event study analysis of People Express. RAND Journal of economics 23, 445-462.

Windle, R., Dresner, M., 1995. The short and long run effects of entry on U.S. domestic routes. Transportation Journal 35, 14-25.

Windle, R., Dresner, M., 1999. Competitive responses to low cost carrier entry. Transportation Research Part E 35, 59-75.

Zhang, A., 1996. An analysis of fortress hubs in network-based markets. Journal of Transport Economics and Policy 30, 293-308.

Zhang, A., Chen, H., 2003. Evolution of China's air transport development and policy towards international liberalisation. Transportation Journal 42, 32-49.

Zhang, Q., Yang, H., Wang, Q., Zhang, A., 2014. Market power and its determinants of the Chinese airline industry. Transportation Research Part A 64, 1-13.

Zhang, Y., Round, D., 2008. China's airline deregulation since 1997 and the driving forces behind the 2002 airline consolidations. Journal of Air Transport Management, 14(3), $130-142$

Zhang Y. and Round D., 2009. Policy implications of the effects of concentration and multimarket contact in China's airline market, Review of Industrial Organization 34, 307-326.

Zhang, Y., Round, D., 2011. Price wars and price collusion in China's airline markets. International Journal of Industrial Organization 29(4), 361-372.

Zou L., Yu C. and Dresner M., 2015. Fleet standardization and airline performance. Journal of Transport Economics and Policy, Vol. 49, forthcoming. 
Table 1. Operating Statistics of Spring Airlines (2006-2013)

\begin{tabular}{llcccccrrr}
\hline Year & & $\mathbf{2 0 0 6}$ & $\mathbf{2 0 0 7}$ & $\mathbf{2 0 0 8}$ & $\mathbf{2 0 0 9}$ & $\mathbf{2 , 0 1 0}$ & $\mathbf{2 0 1 1}$ & $\mathbf{2 0 1 2}$ & $\mathbf{2 0 1 3}$ \\
\hline Traffic & Pax (1,000) & 1,137 & 2,353 & 2,944 & 4,313 & 5,860 & 7,150 & 9,110 & 10,550 \\
& RPK (1,000) & $1,351,676$ & $3,088,694$ & $3,752,937$ & $5,879,433$ & $8,108,636$ & $10,260,720$ & $13,984,300$ & $16,494,090$ \\
& Freight (ton) & 8,137 & 13,641 & 18,073 & 21,945 & 34,931 & 38,651 & 46,800 & 49,232 \\
& RFTK (1,000) & 9,474 & 15,787 & 21,301 & 28,222 & 48,532 & 56,150 & 71,680 & 75,180 \\
\hline & Pax & $0.78 \%$ & $1.39 \%$ & $1.66 \%$ & $2.00 \%$ & $2.36 \%$ & $2.36 \%$ & $3.08 \%$ & $3.22 \%$ \\
Share of & RPK & $0.73 \%$ & $1.42 \%$ & $1.63 \%$ & $2.09 \%$ & $2.47 \%$ & NA & NA & NA \\
Domestic & Freight & $0.32 \%$ & $0.48 \%$ & $0.63 \%$ & $0.69 \%$ & $0.94 \%$ & $1.02 \%$ & $1.20 \%$ & $1.21 \%$ \\
Market & RFTK & $0.25 \%$ & $0.38 \%$ & $0.50 \%$ & $0.60 \%$ & $0.91 \%$ & NA & NA & NA \\
\hline Fleet* & \# of Aircraft & 4 & 8 & 10 & 14 & 20 & 27 & 33 \\
\hline
\end{tabular}

Note: The fleet number reports status at the end of the year. Only one type of aircraft is used by Spring Airlines (A320).

Source: Statistical Data on Civil Aviation of China (2007-2013) 
Table 2. Spring Airline's Operating Statistics at the Route Level

(All of the market shares are computed based on scheduled seats)

\begin{tabular}{|c|c|c|c|c|c|c|}
\hline Year & $\mathbf{2 0 0 6}$ & $\mathbf{2 0 0 7}$ & $\mathbf{2 0 0 8}$ & $\mathbf{2 0 0 9}$ & $\mathbf{2 0 1 0}$ & $\mathbf{2 0 1 1}$ \\
\hline No. of routes & 13 & 13 & 13 & 22 & 38 & 60 \\
\hline $\begin{array}{c}\text { Average Density } \\
\text { (yearly Scheduled Seat) }\end{array}$ & 60092.3 & 89529.2 & 89750.8 & 105169.1 & 113153.7 & 120195.0 \\
\hline Average route Share & $35.3 \%$ & $40.6 \%$ & $42.0 \%$ & $25.5 \%$ & $29.3 \%$ & $30.2 \%$ \\
\hline Average route Share * & $23.5 \%$ & $22.7 \%$ & $24.6 \%$ & $18.1 \%$ & $21.0 \%$ & $19.5 \%$ \\
\hline
\end{tabular}

Source: Compiled by the authors using OAG data.

Note: (1) a route is regarded as served by an airline if its scheduled seats exceed 12,000 per year (or 1,000 per month). A route is defined as an airport-pair.

(2) Average route share is the average market share of Spring in all of the routes it served. Average route share* is the average market share of Spring in routes with at least one competing FSC. This measurement excludes routes that were monopolized by Spring. 
Table 3. Unit Operating Cost Comparison between Spring and the "Big Three" Airlines

\begin{tabular}{|c|c|c|c|c|}
\hline \multirow[t]{2}{*}{ Year 2011} & \multirow[b]{2}{*}{ Spring } & \multirow[b]{2}{*}{ Air China } & \multirow[b]{2}{*}{ China Eastern } & \multirow[b]{2}{*}{ China Southern } \\
\hline & & & & \\
\hline Unit Operating Cost (RMB/ASK) & 0.383 & 0.608 & 0.620 & 0.576 \\
\hline Unit labor cost & 0.044 & 0.081 & 0.068 & NA \\
\hline Unit fuel cost & 0.166 & 0.229 & 0.229 & 0.216 \\
\hline Unit depreciation, Aircraft leasing cost & 0.054 & 0.093 & 0.091 & 0.082 \\
\hline Unit selling and marketing cost & 0.007 & 0.036 & 0.029 & 0.043 \\
\hline \multirow[t]{2}{*}{ Year 2012} & & & & \\
\hline & Spring & Air China & China Eastern & China Southern \\
\hline \multirow{7}{*}{$\begin{array}{r}\text { Unit labor cost } \\
\text { Unit fuel cost } \\
\text { Unit depreciation, Aircraft leasing cost } \\
\text { Unit selling and marking cost }\end{array}$} & 0.356 & 0.574 & 0.605 & 0.565 \\
\hline & 0.050 & 0.085 & 0.090 & NA \\
\hline & 0.147 & 0.221 & 0.218 & 0.221 \\
\hline & 0.049 & 0.090 & 0.092 & 0.078 \\
\hline & 0.008 & 0.035 & 0.027 & 0.042 \\
\hline & & & & \\
\hline & Spring & Air China & China Eastern & China Southern \\
\hline \multirow{5}{*}{$\begin{array}{r}\text { Unit labor cost } \\
\text { Unit fuel cost } \\
\text { Unit depreciation, Aircraft leasing cost } \\
\text { Unit selling and marking cost }\end{array}$} & 0.346 & 0.535 & 0.588 & 0.526 \\
\hline & 0.045 & NA & 0.088 & NA \\
\hline & 0.140 & NA & 0.202 & 0.190 \\
\hline & 0.047 & NA & 0.089 & 0.076 \\
\hline & 0.009 & NA & 0.027 & 0.042 \\
\hline
\end{tabular}

Source: Data for Spring are retrieved from its IPO prospectus published in April 2014; data for the "Big Three" are retrieved from their company's annual reports Note: All of the unit cost items are in RMB/ASK; ASK is available seat kilometers. 
Table 4. Descriptive Statistics for the Sample Data Used in Fare Regression

\begin{tabular}{lrrrrr}
\hline \multicolumn{1}{c}{ Variable } & No. of Obs & \multicolumn{1}{c}{ Mean } & Std. Dev. & \multicolumn{1}{c}{ Min } & \multicolumn{1}{c}{ Max } \\
\hline Yield & 19,118 & 0.121 & 0.048 & 0.037 & 0.642 \\
Dist & 19,118 & 1,105 & 540 & 159 & 3,292 \\
HHI & 19,118 & 4,610 & 2,151 & 1,411 & 10,000 \\
AirShareM & 19,118 & 0.067 & 0.070 & 0.001 & 0.578 \\
AirportVol & 19,118 & 497,946 & 647,160 & 290 & $7,400,000$ \\
Spring & 19,118 & 0.052 & 0.221 & 0 & 1 \\
Tour & 19,118 & 0.266 & 0.442 & 0 & 1 \\
HSR_1 & 19,118 & 0.017 & 0.131 & 0 & 1 \\
HSR_2 & 19,118 & 0.009 & 0.094 & 0 & 1 \\
\hline
\end{tabular}


Table 5.1 OLS and Fixed Effect Estimation of the Yield Equation

\begin{tabular}{|c|c|c|c|c|c|c|c|c|c|c|}
\hline & \multicolumn{2}{|c|}{ Air China } & \multicolumn{2}{|c|}{ China Eastern } & \multicolumn{2}{|c|}{ China Southern } & \multicolumn{2}{|c|}{ Hainan } & \multicolumn{2}{|c|}{ FSC Average } \\
\hline & OLS & Fixed effect & OLS & Fixed effect & OLS & Fixed effect & OLS & Fixed effect & OLS & Fixed effect \\
\hline InDist & $\begin{array}{c}-0.466 * * * \\
(0.006)\end{array}$ & & $\begin{array}{c}-0.502 * * * \\
(0.006)\end{array}$ & & $\begin{array}{c}-0.435^{* * *} \\
(0.004)\end{array}$ & & $\begin{array}{c}-0.381 * * * \\
(0.006)\end{array}$ & & $\begin{array}{c}-0.466 * * * \\
(0.003)\end{array}$ & \\
\hline $\ln H H I$ & $\begin{array}{c}0.172 * * * \\
(0.008)\end{array}$ & $\begin{array}{c}0.152 * * * \\
(0.010)\end{array}$ & $\begin{array}{c}0.223^{* * * *} \\
(0.006)\end{array}$ & $\begin{array}{c}0.186^{* * * *} \\
(0.008)\end{array}$ & $\begin{array}{c}0.217 * * * \\
(0.005)\end{array}$ & $\begin{array}{c}0.174 * * * \\
(0.006)\end{array}$ & $\begin{array}{c}0.190 * * * \\
(0.008)\end{array}$ & $\begin{array}{c}0.175^{* * *} \\
(0.026)\end{array}$ & $\begin{array}{c}0.187 * * * \\
(0.004)\end{array}$ & $\begin{array}{c}0.178 * * * \\
(0.004)\end{array}$ \\
\hline InAirShareM & $\begin{array}{c}0.099 * * * \\
(0.003)\end{array}$ & $\begin{array}{c}0.056^{* * * *} \\
(0.007)\end{array}$ & $\begin{array}{c}0.012 * * * \\
(0.003)\end{array}$ & $\begin{array}{c}0.009 \\
(0.007)\end{array}$ & $\begin{array}{c}-0.035^{* * *} \\
(0.003)\end{array}$ & $\begin{array}{c}0.029 * * * \\
(0.006)\end{array}$ & $\begin{array}{c}0.025^{* * *} \\
(0.003)\end{array}$ & $\begin{array}{l}-0.001 \\
(0.013)\end{array}$ & $\begin{array}{c}0.035^{* * * *} \\
(0.002)\end{array}$ & $\begin{array}{c}0.045^{* * *} \\
(0.003)\end{array}$ \\
\hline InAirportVol & $\begin{array}{c}0.008 * * \\
(0.003)\end{array}$ & $\begin{array}{c}0.113^{* * * *} \\
(0.008)\end{array}$ & $\begin{array}{l}-0.001 \\
(0.003)\end{array}$ & $\begin{array}{c}0.027 * * * \\
(0.007)\end{array}$ & $\begin{array}{l}-0.001 \\
(0.002)\end{array}$ & $\begin{array}{c}0.073 * * * \\
(0.005)\end{array}$ & $\begin{array}{c}0.033^{* * *} * \\
(0.003)\end{array}$ & $\begin{array}{c}0.136^{* * * *} \\
(0.022)\end{array}$ & $\begin{array}{c}0.002 \\
(0.002)\end{array}$ & $\begin{array}{c}0.065^{* * *} * \\
(0.004)\end{array}$ \\
\hline Tour & $\begin{array}{c}0.015^{* * *} \\
(0.006)\end{array}$ & & $\begin{array}{c}-0.022 * * * \\
(0.005)\end{array}$ & & $\begin{array}{c}-0.041 * * * \\
(0.004)\end{array}$ & & $\begin{array}{c}-0.037 * * * \\
(0.006)\end{array}$ & & $\begin{array}{c}-0.050 * * * \\
(0.003)\end{array}$ & \\
\hline HSR_1 & $\begin{array}{c}-0.118^{* * *} \\
(0.020)\end{array}$ & $\begin{array}{c}-0.051 * * * \\
(0.015)\end{array}$ & $\begin{array}{c}-0.140 * * * \\
(0.010)\end{array}$ & $\begin{array}{c}-0.095 * * * \\
(0.013)\end{array}$ & $\begin{array}{c}-0.194 * * * \\
(0.011)\end{array}$ & $\begin{array}{c}-0.116^{* * *} \\
(0.014)\end{array}$ & $\begin{array}{c}-0.061 * * \\
(0.030)\end{array}$ & $\begin{array}{l}-0.092 \\
(0.074)\end{array}$ & $\begin{array}{c}-0.162 * * * \\
(0.010)\end{array}$ & $\begin{array}{c}-0.104 * * * \\
(0.011)\end{array}$ \\
\hline Spring & $\begin{array}{c}0.003 \\
(0.012)\end{array}$ & $\begin{array}{c}-0.051 * * * \\
(0.012)\end{array}$ & $\begin{array}{c}0.041^{* * *} \\
(0.006)\end{array}$ & $\begin{array}{c}-0.034 * * * \\
(0.007)\end{array}$ & $\begin{array}{c}0.051^{* * *} \\
(0.008)\end{array}$ & $\begin{array}{l}-0.000 \\
(0.009)\end{array}$ & $\begin{array}{l}-0.0009 \\
(0.017)\end{array}$ & $\begin{array}{c}-0.062^{* * *} \\
(0.018)\end{array}$ & $\begin{array}{c}0.022^{* * *} \\
(0.005)\end{array}$ & $\begin{array}{c}-0.023^{* * *} \\
(0.007)\end{array}$ \\
\hline CA & & & $\begin{array}{c}0.077 * * * \\
(0.005)\end{array}$ & $\begin{array}{l}-0.007 \\
(0.007)\end{array}$ & $\begin{array}{c}0.042^{* * *} * \\
(0.004)\end{array}$ & $\begin{array}{l}-0.006 \\
(0.006)\end{array}$ & $\begin{array}{c}0.076^{* * * *} \\
(0.006)\end{array}$ & $\begin{array}{c}0.023 \\
(0.022)\end{array}$ & & \\
\hline MU & $\begin{array}{l}-0.005 \\
(0.005)\end{array}$ & $\begin{array}{c}0.013 \\
(0.008)\end{array}$ & & & $\begin{array}{c}-0.046^{* * *} * \\
(0.004)\end{array}$ & $\begin{array}{c}-0.022 * * * \\
(0.005)\end{array}$ & $\begin{array}{c}-0.090 * * * \\
(0.006)\end{array}$ & $\begin{array}{c}-0.042 * * \\
(0.018)\end{array}$ & & \\
\hline $\mathbf{C Z}$ & $\begin{array}{c}0.007 \\
(0.005)\end{array}$ & $\begin{array}{l}-0.012 \\
(0.009)\end{array}$ & $\begin{array}{c}0.015^{* * * *} \\
(0.005)\end{array}$ & $\begin{array}{c}0.011 \\
(0.008)\end{array}$ & & & $\begin{array}{c}-0.013 * * \\
(0.006)\end{array}$ & $\begin{array}{c}0.038 * * \\
(0.019)\end{array}$ & & \\
\hline HU & $\begin{array}{c}0.007 \\
(0.005)\end{array}$ & $\begin{array}{c}-0.020 * \\
(0.008)\end{array}$ & $\begin{array}{c}-0.053 * * * \\
(0.004)\end{array}$ & $\begin{array}{l}-0.007 \\
(0.008)\end{array}$ & $\begin{array}{c}-0.028 * * * \\
(0.004)\end{array}$ & $\begin{array}{c}-0.033 * * * \\
(0.005)\end{array}$ & & & & \\
\hline Constant & $-0.426^{* * *}$ & $-4.950 * * *$ & $-0.832 * * *$ & $-4.292 * * *$ & $-1.304 * * *$ & $-4.667 * * *$ & $-1.830 * * *$ & $-5.808 * * *$ & $-0.688 * * *$ & $-4.556^{* * *}$ \\
\hline
\end{tabular}




\begin{tabular}{c|cc|cc|cc|cc|cc} 
& $(0.097)$ & $(0.139)$ & $(0.076)$ & $(0.121)$ & $(0.054)$ & $(0.091)$ & $(0.088)$ & $(0.381)$ & $(0.047)$ & $(0.071)$ \\
\hline sigma_u & & 0.327 & & 0.286 & & 0.314 & 0.303 & & 0.32 & \\
sigma_e & & 0.116 & & 0.12 & & 0.122 & 0.143 & \\
No. of Obs & 6672 & 6672 & 8966 & 8966 & 13025 & 13025 & 6583 & 6583 & 19118 \\
R-Squared & 0.697 & 0.487 & 0.741 & 0.456 & 0.692 & 0.428 & 0.598 & 0.491 & 0.700 & 0.441 \\
\hline
\end{tabular}

Notes: $(1) *$ significant at $10 \%$ level; ** significant at $5 \%$ level; *** significant at $1 \%$ level;

(2) The number in brackets is the standard error;

(3) Quarterly and yearly dummy variables are included in the estimation but are not reported to conserve space. We have also tested alternative specifications with monthly dummies (instead of quarterly dummies), which led to no qualitative changes in the estimation;

(4) Distance and tourist are time invariant variables, hence cannot be estimated by the fixed effect model.

Table 5.2. Fixed Effect Estimation of the Yield Equation with Alternative High Speed Rail Definition

\begin{tabular}{c|c|c|c|c|c}
\hline & Air China & China Eastern & China Southern & Hainan & FSC Average \\
\hline \multirow{2}{*}{ InHHI } & $0.151 * * *$ & $0.184 * * *$ & $0.173 * * *$ & $0.175^{* * *}$ & $0.176^{* * *}$ \\
& $(0.010)$ & $(0.008)$ & $(0.005)$ & $(0.026)$ & $(0.004)$ \\
InAirShareM & $0.057 * * *$ & 0.010 & $0.028 * * *$ & -0.001 & $0.045^{* * *}$ \\
& $(0.007)$ & $(0.008)$ & $(0.006)$ & $(0.013)$ & $(0.003)$ \\
InAirportVol & $0.113 * * *$ & $0.027 * * *$ & $0.072 * * *$ & $0.136 * * *$ & $0.065 * * *$ \\
& $(0.007)$ & $(0.007)$ & $(0.006)$ & $(0.022)$ & $(0.004)$ \\
HSR_2 & $-0.046^{* * *}$ & $-0.065 * * *$ & $-0.0967 * * *$ & -0.092 & $-0.076^{* * *}$ \\
& $(0.016)$ & $(0.017)$ & $(0.014)$ & $(0.074)$ & $(0.014)$ \\
Spring & $-0.051 * * *$ & $-0.032 * * *$ & -0.000 & $-0.062 * * *$ & $-0.021 * * *$ \\
& $(0.012)$ & $(0.008)$ & $(0.009)$ & $(0.018)$ & $(0.007)$ \\
CA & & -0.008 & -0.007 & 0.023 &
\end{tabular}




\begin{tabular}{c|c|c|c|c|c} 
MU & 0.013 & & $-0.022^{* * *}$ & $-0.042^{* *}$ & \\
& $(0.008)$ & & $(0.005)$ & $(0.018)$ & \\
$\mathbf{C Z}$ & -0.012 & 0.011 & & $0.038^{* *}$ & \\
& $(0.009)$ & $(0.008)$ & & $(0.019)$ & \\
HU & $-0.020^{*}$ & -0.005 & $-0.032^{* * *}$ & & \\
& $(0.008)$ & $(0.008)$ & $(0.005)$ & & \\
Constant & $-4.950^{* * *}$ & $-4.279^{* * *}$ & $-4.652^{* * *}$ & $-5.808^{* * *}$ & $-4.544^{* * *}$ \\
& $(0.139)$ & $(0.121)$ & $(0.091)$ & $(0.381)$ & $(0.071)$ \\
\hline sigma_u & 0.327 & 0.285 & 0.314 & 0.303 & 0.32 \\
sigma_e & 0.116 & 0.120 & 0.122 & 0.143 & 0.123 \\
No. of Obs & 6672 & 8966 & 13025 & 6583 & 19118 \\
R-Squared & 0.487 & 0.454 & 0.426 & 0.491 & 0.439 \\
\hline
\end{tabular}

Notes: the notes (1) to (3) of Table 5.1 also apply here. 
Table 6. Descriptive Statistics for the Variables Used in the Probit Estimation

\begin{tabular}{lrrrrr}
\hline Variable & Obs & \multicolumn{1}{c}{ Mean } & Std. Dev. & \multicolumn{1}{c}{ Min } & \multicolumn{1}{c}{ Max } \\
\hline Entry & 496 & 0.123 & 0.329 & 0 & 1 \\
Dist & 496 & 1044.93 & 529.91 & 159 & 3388 \\
AirportVol & 496 & 29100000 & 55000000 & 44182 & 561000000 \\
HHI & 496 & 6452 & 2583 & 2099 & 10000 \\
Density1 & 496 & 0.040 & 0.197 & 0 & 1 \\
Density2 & 496 & 0.060 & 0.239 & 0 & 1 \\
Density3 & 496 & 0.198 & 0.399 & 0 & 1 \\
Ownhub & 496 & 0.133 & 0.340 & 0 & 1 \\
Otherhub & 496 & 0.222 & 0.416 & 0 & 1 \\
HSR1 & 496 & 0.041 & 0.199 & 0 & 1 \\
\hline
\end{tabular}

Table 7. Estimation Result of the Probit Model

\begin{tabular}{lc|lc}
\hline & Coef. & & Coef. \\
\hline InDist & $0.762^{* * *}$ & Density3 & -0.029 \\
& $(0.280)$ & & $(0.336)$ \\
InAirportVol & $-0.230^{* * *}$ & Ownhub & $2.446 * * *$ \\
& $(0.081)$ & & $(0.295)$ \\
InHHI & 0.070 & Otherhub & -0.141 \\
& $(0.420)$ & & $(0.370)$ \\
Density1 & 0.793 & HSR1 & 0.141 \\
& $(0.630)$ & & \\
& & & $(0.460)$ \\
Density2 & $0.875^{*}$ & Constant & -4.398 \\
& $(0.422)$ & & $(4.670)$ \\
\hline
\end{tabular}

Note: * significant at $10 \%$ level; ** significant at $5 \%$ level; *** significant at $1 \%$ level. The number in brackets is the standard error.

Table 8. Pattern of Routes Served by Spring Airlines in 2012

\begin{tabular}{|l|c|c|}
\hline Route Density Rank & $\begin{array}{c}\text { Routes Served by } \\
\text { Spring Airlines }\end{array}$ & Percentage \\
\hline $1-50$ & 12 & $23 \%$ \\
\hline $51-150$ & 8 & $15 \%$ \\
\hline Other & 32 & $62 \%$ \\
\hline
\end{tabular}

Source: Compiled by the author using OAG data 


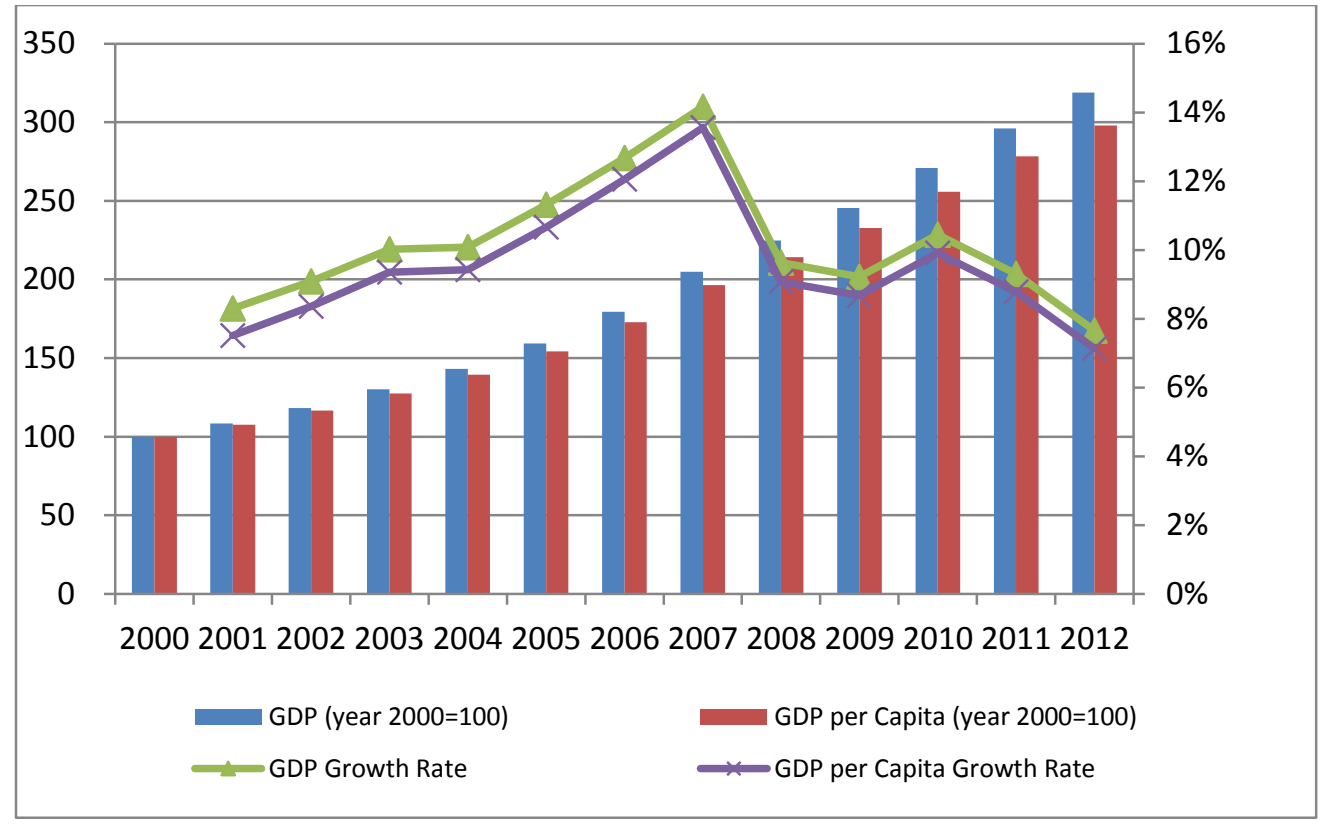

(a) GDP and GDP per Capita of China

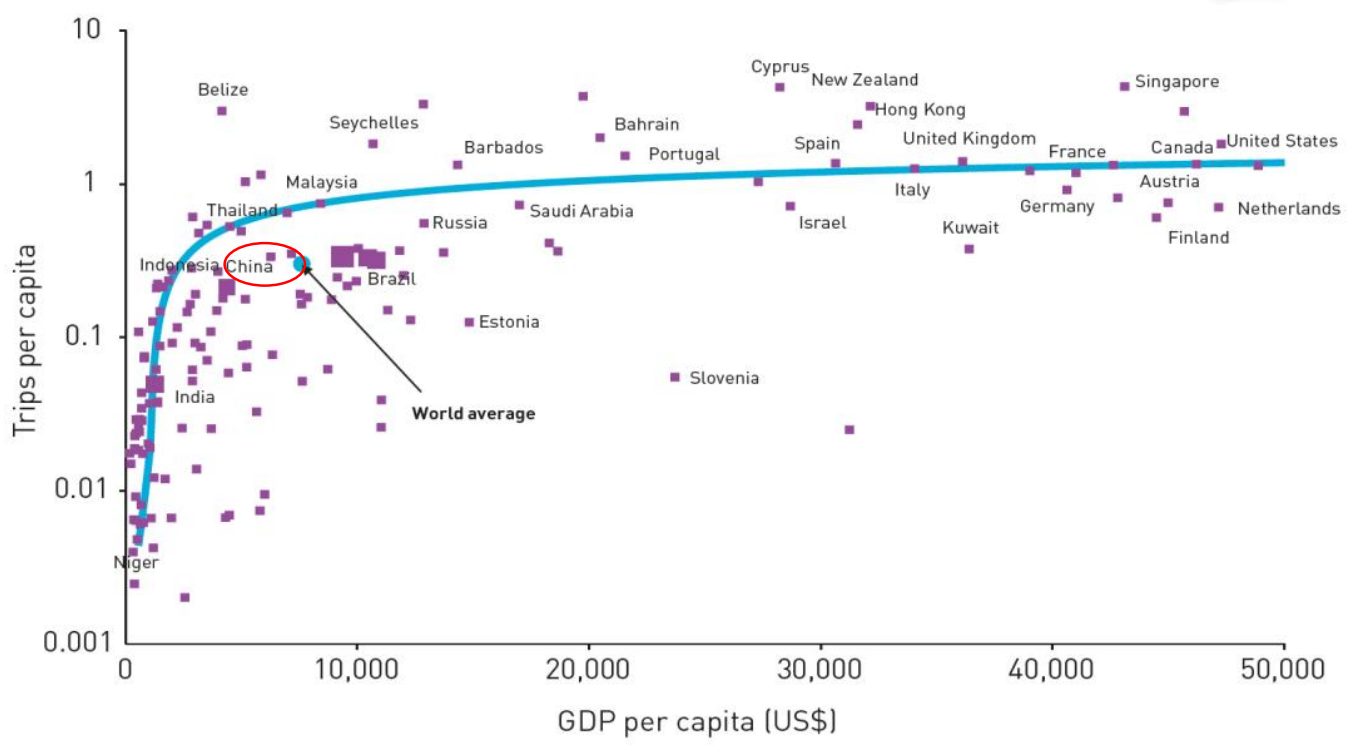

(b) Air travel propensity 2012

Figure 1. Economic growth of China and its air passenger growth potential

Source: The data for Panel (a) are compiled from the National Bureau of Statistics of China; Panel (b) is retrieved from the report "Aviation Benefits Beyond Borders" published by Air Transport Action Group (ATAG) in April 2014. 


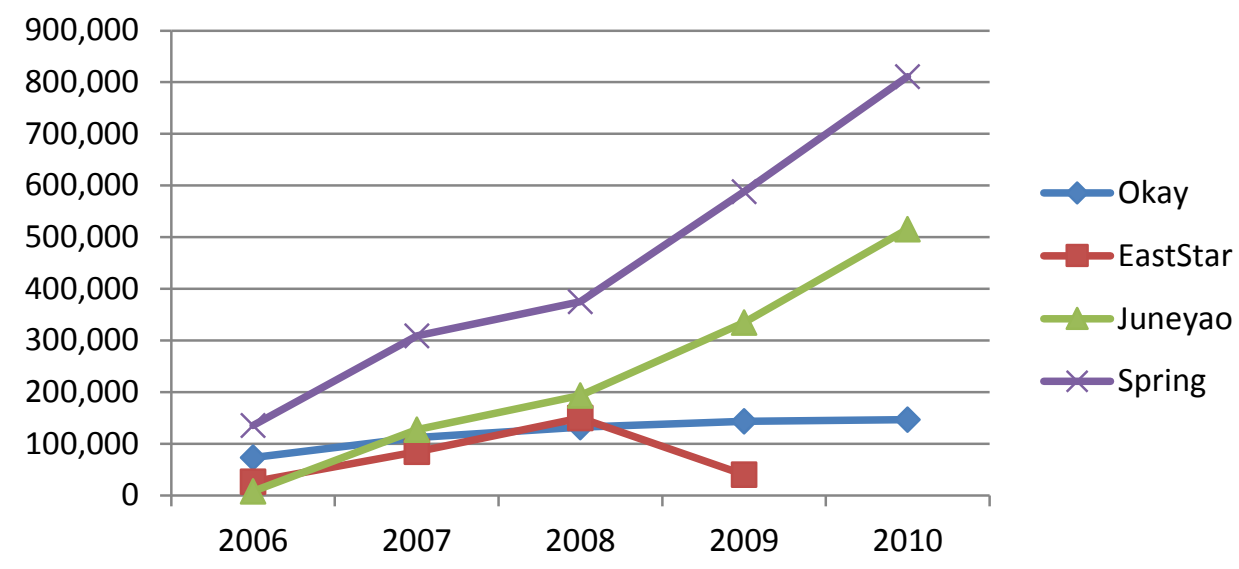

Figure 2. RPK $(10,000)$ for Chinese Private Airlines from 2006 to 2010

Source: Statistical Data on Civil Aviation of China

Note: Okay Airways started to offer commercial services in March 2005. East Star Airlines started commercial operation in 2006, and was liquidated in March 2009. Juneyao Airlines was established in 2005. 


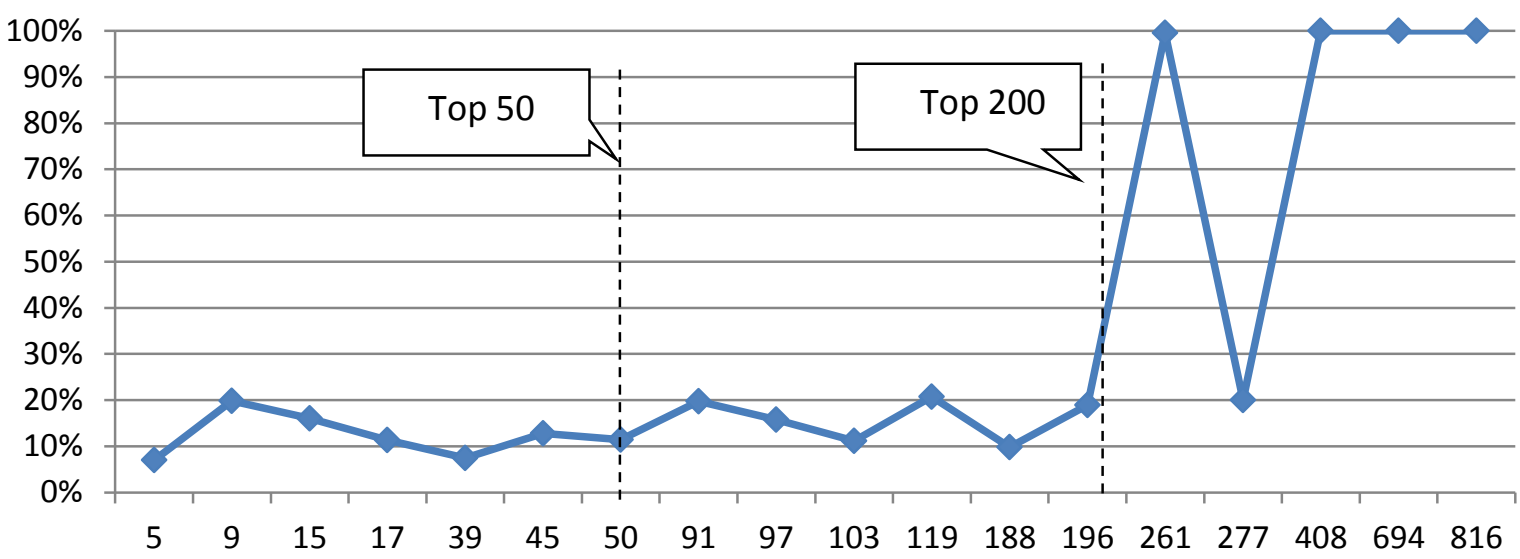

(a). Second Quarter in 2009

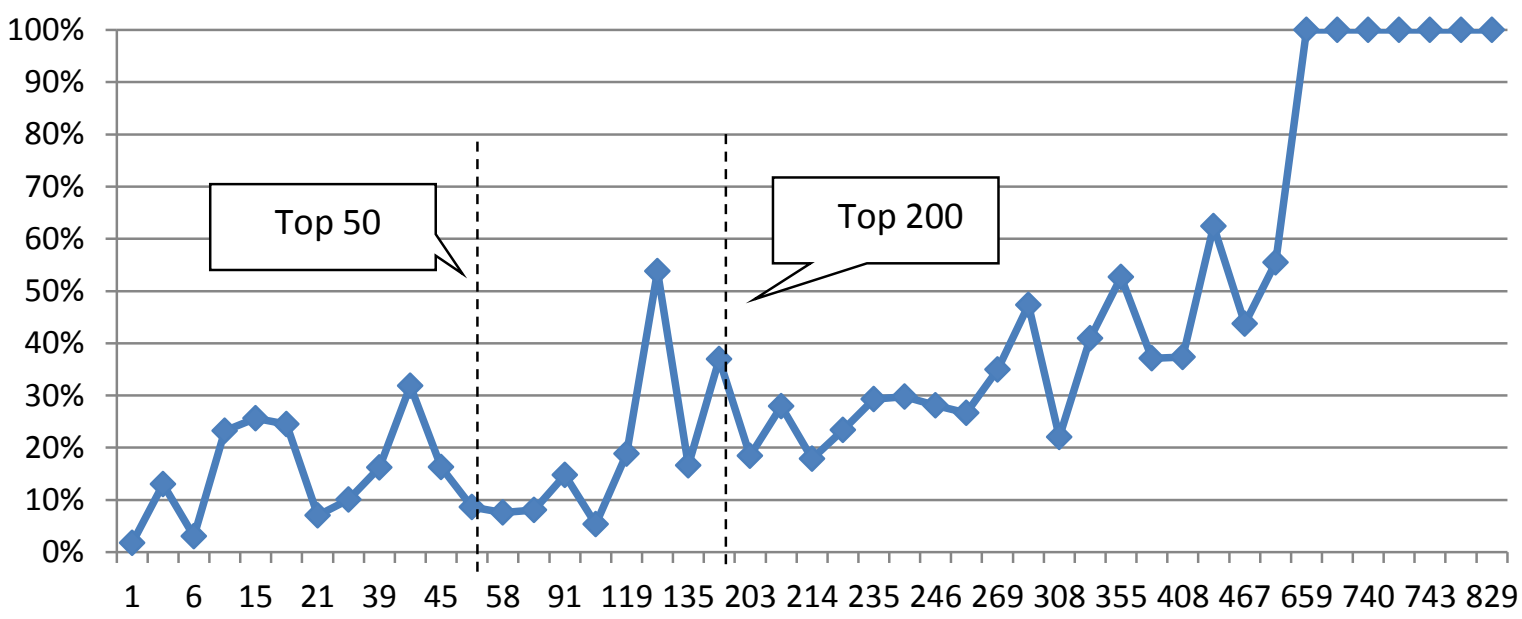

(b). Second Quarter in 2012

Figure 3. Route Capacity Share of Spring Airlines

Source: compiled by the authors using OAG data.

Note: The horizontal axis indicates the rank of the route. For example, " 5 " means the 5 th densest route in the domestic market. 
Appendix: Yield Regression Using FSCs' Flight Frequencies Instead of Airline Dummies

\begin{tabular}{|c|c|c|c|c|c|c|c|c|}
\hline \multirow{3}{*}{ InDist } & \multicolumn{2}{|c|}{ Air China } & \multicolumn{2}{|c|}{ China Eastern } & \multicolumn{2}{|c|}{ China Southern } & \multicolumn{2}{|c|}{ Hainan } \\
\hline & OLS & Fixed effect & OLS & Fixed effect & OLS & Fixed effect & OLS & Fixed effect \\
\hline & $\begin{array}{c}-0.468 * * * \\
(0.006)\end{array}$ & & $\begin{array}{c}-0.498 * * * \\
(0.005)\end{array}$ & & $\begin{array}{c}-0.437 * * * \\
(0.004)\end{array}$ & & $\begin{array}{c}-0.382 * * * \\
(0.006)\end{array}$ & \\
\hline $\operatorname{lnHHI}$ & $\begin{array}{c}0.172^{* * * *} \\
(0.008)\end{array}$ & $\begin{array}{c}0.137 * * * \\
(0.010)\end{array}$ & $\begin{array}{c}0.222 * * * \\
(0.006)\end{array}$ & $\begin{array}{c}0.179 * * * \\
(0.008)\end{array}$ & $\begin{array}{c}0.217 * * * \\
(0.005)\end{array}$ & $\begin{array}{c}0.171 * * * \\
(0.006)\end{array}$ & $\begin{array}{c}0.182^{* * *} \\
(0.008)\end{array}$ & $\begin{array}{c}0.163^{* * * *} \\
(0.010)\end{array}$ \\
\hline InAirShareM & $\begin{array}{c}0.098 * * * \\
(0.003)\end{array}$ & $\begin{array}{c}0.058 * * * \\
(0.007)\end{array}$ & $\begin{array}{c}0.010^{* * * *} \\
(0.003)\end{array}$ & $\begin{array}{c}0.009 \\
(0.007)\end{array}$ & $\begin{array}{c}-0.034 * * * \\
(0.003)\end{array}$ & $\begin{array}{c}0.031 * * * \\
(0.006)\end{array}$ & $\begin{array}{c}0.021 * * * \\
(0.003)\end{array}$ & $\begin{array}{l}-0.004 \\
(0.007)\end{array}$ \\
\hline InAirportVol & $\begin{array}{c}0.008 * * \\
(0.003)\end{array}$ & $\begin{array}{c}0.120^{* * *} \\
(0.008)\end{array}$ & $\begin{array}{c}-0.006^{* *} \\
(0.003)\end{array}$ & $\begin{array}{c}0.030 * * * \\
(0.007)\end{array}$ & $\begin{array}{l}-0.002 \\
(0.002)\end{array}$ & $\begin{array}{c}0.076 * * * \\
(0.005)\end{array}$ & $\begin{array}{c}0.034 * * * \\
(0.003)\end{array}$ & $\begin{array}{c}0.143 * * * \\
(0.010)\end{array}$ \\
\hline Tour & $\begin{array}{c}0.015 * * * \\
(0.006)\end{array}$ & & $\begin{array}{c}-0.011^{* *} \\
(0.005)\end{array}$ & & $\begin{array}{c}-0.035 * * * \\
(0.004)\end{array}$ & & $\begin{array}{c}-0.028 * * * \\
(0.006)\end{array}$ & \\
\hline HSR_1 & $\begin{array}{c}-0.118 * * * \\
(0.020)\end{array}$ & $\begin{array}{c}-0.047 * * * \\
(0.015)\end{array}$ & $\begin{array}{c}-0.135^{* * * *} \\
(0.010)\end{array}$ & $\begin{array}{c}-0.093 * * * \\
(0.013)\end{array}$ & $\begin{array}{c}-0.185^{* * * *} \\
(0.011)\end{array}$ & $\begin{array}{c}-0.119^{* * *} \\
(0.014)\end{array}$ & $\begin{array}{c}-0.053 * * \\
(0.030)\end{array}$ & $\begin{array}{c}-0.088^{* * *} \\
(0.028)\end{array}$ \\
\hline Spring & $\begin{array}{c}0.006 \\
(0.012)\end{array}$ & $\begin{array}{c}-0.053 * * * \\
(0.012)\end{array}$ & $\begin{array}{c}0.045 * * * \\
(0.006)\end{array}$ & $\begin{array}{c}-0.035 * * * \\
(0.007)\end{array}$ & $\begin{array}{c}0.061 * * * \\
(0.008)\end{array}$ & $\begin{array}{l}-0.001 \\
(0.009)\end{array}$ & $\begin{array}{l}-0.006 \\
(0.017)\end{array}$ & $\begin{array}{c}-0.066 * * * \\
(0.021)\end{array}$ \\
\hline InCA_freq & & & $\begin{array}{c}0.023 * * * \\
(0.001)\end{array}$ & $\begin{array}{c}-0.006 * * * \\
(0.002)\end{array}$ & $\begin{array}{c}0.014 * * * \\
(0.001)\end{array}$ & $\begin{array}{c}-0.005^{* *} \\
(0.002)\end{array}$ & $\begin{array}{c}0.020 * * * \\
(0.001)\end{array}$ & $\begin{array}{c}0.000 \\
(0.003)\end{array}$ \\
\hline InMU_freq & $\begin{array}{l}-0.002 \\
(0.001)\end{array}$ & $\begin{array}{c}0.002 \\
(0.002)\end{array}$ & & & $\begin{array}{c}-0.012 * * * \\
(0.001)\end{array}$ & $\begin{array}{c}-0.008 * * * \\
(0.002)\end{array}$ & $\begin{array}{c}-0.025^{* * *} \\
(0.001)\end{array}$ & $\begin{array}{c}-0.022^{* *} \\
(0.003)\end{array}$ \\
\hline InCZ_freq & $\begin{array}{c}0.002 \\
(0.001)\end{array}$ & $\begin{array}{c}-0.012 * * * \\
(0.003)\end{array}$ & $\begin{array}{c}0.004 * * * \\
(0.001)\end{array}$ & $\begin{array}{l}-0.002 \\
(0.002)\end{array}$ & & & $\begin{array}{c}-0.007 * * * \\
(0.001)\end{array}$ & $\begin{array}{c}0.004 \\
(0.003)\end{array}$ \\
\hline InHU_freq & $\begin{array}{c}0.003 * * \\
(0.001)\end{array}$ & $\begin{array}{c}-0.010^{* * * *} \\
(0.003)\end{array}$ & $\begin{array}{c}-0.016 * * * \\
(0.001)\end{array}$ & $\begin{array}{l}-0.004 \\
(0.002)\end{array}$ & $\begin{array}{c}-0.009 * * * \\
(0.001)\end{array}$ & $\begin{array}{c}-0.013 * * * \\
(0.002)\end{array}$ & & \\
\hline Constant & $-0.410 * * *$ & $-4.868 * * *$ & $-0.800 * * *$ & $-4.259 * * *$ & $-1.281 * * *$ & $-4.665 * * *$ & $-1.778 * * *$ & $-5.771 * * *$ \\
\hline
\end{tabular}




\begin{tabular}{c|cc|cc|cc|cc} 
& $(0.096)$ & $(0.139)$ & $(0.075)$ & $(0.120)$ & $(0.052)$ & $(0.090)$ & $(0.084)$ & $(0.162)$ \\
\hline sigma_u & & 0.327 & & 0.286 & & 0.314 & & 0.305 \\
sigma_e & & 0.116 & & 0.120 & & 0.121 & & 0.142 \\
No. of Obs & 6672 & 6672 & 8966 & 8966 & 13025 & 13025 & 6583 & 6583 \\
R-Squared & 0.695 & 0.488 & 0.745 & 0.457 & 0.694 & 0.430 & 0.606 & 0.493 \\
\hline
\end{tabular}

